\title{
Ocorrência e tratamento de miíases cutâneas em ovinos criados em condições semiáridas no norte de Minas Gerais ${ }^{1}$
}

\author{
Eduardo R. Duarte ${ }^{2 *}$, Fabrício T. da Rocha², Lucas M. Teixeira², Rayana B. Silva ${ }^{2}$, \\ Flávia A. Nogueira ${ }^{2}$, Nathalie O. Silva ${ }^{2}$ e Anna C. Almeida ${ }^{2}$
}

\begin{abstract}
Duarte E.R., Rocha F.T., Teixeira L.M., Silva R.B., Nogueira F.A., Silva N.O. \& Almeida A.C. 2012. [Occurrence and treatment of cutaneous myiasis in sheep reared in semi-arid conditions in northern Minas Gerais.] Ocorrência e tratamento de míases cutâneas em ovinos criados em condições semiáridas no norte de Minas Gerais. Pesquisa Veterinária Brasileira 32(6):490-494. Instituto de Ciências Agrárias, Universidade Federal de Minas Gerais, Av. Universitária 1000, Bairro Universitário, Montes Claros, MG 39400006, Brazil. E-mail: duartevet@hotmail.com

Cutaneous myiasis was investigated in 10 sheep herds during one year in northern Minas Gerais, Brazil, and factors related to its occurrence were analyzed. The sheep were predominantly hybrid Saint Inês, bred in semi-extensive systems. A total of 50 cases were registered and the highest incidence occurred during March (22\%) and April (18\%), months with high temperatures and high relative humidity of the air. There was no influence of sex and age for the occurrence of myiasis. The lesions were mostly found on the legs $(34 \%$ of the cases). Pododermatitis (38\% of the cases), omphalophlebitis (10\%), lymphadenitis $(6 \%)$ and dermatobiosis $(6 \%)$ were the predisposing factors more frequently associated with myiasis. The myiasis was not correctly treated by the owners, but after implantation of a correct therapy, $92 \%$ of the lesions presented cure within 7 to 30 days. The results show the importance of preventive strategies based on the predisposing factors identified in this study. The constant inspection, identifying wounds and precociously treating the lesions, should be routine especially at the end of rainy season and when predisposing factors are present.
\end{abstract}

INDEX TERMS: Cochliomyia hominivorax, miyasis, sheep, predisposing factors, semiarid.

RESUMO.- A ocorrência de miíases cutâneas foi verificada em 10 diferentes criatórios de ovinos no norte de Minas Gerais, Brasil, durante o período de um ano, onde foram analisados os fatores relacionados a essas parasitoses. Os rebanhos possuíam predominantemente animais mestiços Santa Inês, criados em sistemas semiextensivo. Foram registrados 50 casos e a maior incidência foi observada nos meses de março (22\%) e abril (18\%), períodos de maiores temperaturas e umidade relativa do ar. As patas foram as regiões mais frequentemente acometidas (34\% dos casos). As lesões por pododermatites ( $38 \%$ dos casos), onfaloflebites $(10 \%)$, linfadenite $(6 \%)$ e dermatobiose $(6 \%)$ foram os fatores mais frequentemente relacionados às mííases. As

\footnotetext{
${ }^{1}$ Recebido em 30 de agosto de 2011.

Aceito para publicação em 9 de janeiro de 2012.

${ }^{2}$ Instituto de Ciências Agrárias, Universidade Federal de Minas Gerais, Av. Universitária 1000, Montes Claros, MG 39400-006, Brasil. * Autor para correspondência: duartevet@hotmail.com
}

taxas de ocorrência não diferiram quanto ao sexo e idade dos animais. Foi constatado que a maioria dos proprietários não realizava o tratamento das miíases de forma correta, sendo que após a implantação de uma terapia preconizada nesta pesquisa, $92 \%$ das lesões apresentaram cura entre sete e trinta dias. Os resultados apontam a importância de estratégias para prevenção baseadas nos fatores relacionados neste estudo. A inspeção constante dos ovinos, identificando-se os ferimentos e tratando-se as lesões precocemente, devem constituir práticas rotineiras, principalmente no período chuvoso e quando estão presentes nas patas dos animais.

TERMOS DE INDEXAÇÃO: Cochliomyia hominivorax, miíases, ovinocultura, fatores predisponentes, sazonalidade, semiárido.

\section{INTRODUÇÃO}

As miíases são lesões causadas pela invasão do tecido cutâneo por larvas de insetos dípteros que se alimentam de te- 
cidos vivos, não necrosados (biontófagas), ou em necrose (necrobiontófagas) (Fortes 2004, Bowman et al. 2006). Essas larvas são os ectoparasitos mais frequentes nos plantéis de ovinos em regiões tropicais e sub-tropicais e responsáveis por grandes perdas econômicas (Madeira et al. 2000).

A mosca Cochliomyia hominivorax (Coquerel), conhecida como mosca das bicheiras, causa grandes prejuízos à pecuária. As larvas parasitam animais de sangue quente e produzem feridas em animais domésticos, selvagens e até mesmo em humanos (Guimarães \& Papavero 1999). É um parasito que requer tecido vivo como alimento. Vinte e quatro horas após a postura, que geralmente ocorre nas bordas das feridas, os ovos eclodem o primeiro estágio da larva que penetra no tecido vivo para se alimentar. Até o sétimo dia de parasitismo as larvas escavam o tecido, aumentando e aprofundando ainda mais a ferida. Nas lesões observa-se secreção serosa e sanguinolenta, de cheiro pútrido característico, que atrai novas posturas, resultando em infestações múltiplas com centenas a milhares de larvas de diferentes estádios (Fortes 2004, Bowman et al. 2006).

Existem situações em que, dependendo da localização, as infestações se tornam profundas, provocando a morte dos animais por hemorragia ou inviabilizando-os quando destrói a glândula mamária, o sistema reprodutor ou locomotor. Especialmente em pequenos ruminantes, como os ovinos, as larvas das moscas podem destruir muitos tecidos em períodos inferiores a 24 horas e na maioria das vezes o animal fica mutilado (Snoep et al. 2002, Teixeira et al. 2008).

As miíases em ovinos são frequentemente relatadas por criadores em regiões tropicais. Entretanto, os fatores predisponentes para esses pequenos ruminantes e as medidas profiláticas e curativas não estão completamente estabelecidas. $\mathrm{O}$ conhecimento dos aspectos epidemiológicos das mí́ases em ovinos é fundamental para adoção de medidas preventivas e de controle, uma vez que nesses pequenos ruminantes as larvas podem ocasionar rápidas e significativas perdas de tecidos. 0 objetivo neste estudo foi relatar e caracterizar a ocorrência de miíases em rebanhos de ovinos criados em condições tropicais semiáridas.

\section{MATERIAL E MÉTODOS}

Durante o período de setembro de 2006 a agosto de 2007, foram realizadas visitas mensais em 10 diferentes criatórios de ovinos no norte de Minas Gerais, pertencentes aos municípios de Montes Claros, Coração de Jesus, Francisco Sá e Janaúba. A região está localizada a aproximadamente 1640'02" de latitude Sul, 4351'23" de longitude Leste de Greenwich e a aproximadamente $465 \mathrm{~m}$ de altitude. 0 clima da região é caracterizado como tropical típico, quente e semi-úmido, com uma estação chuvosa curta (de novembro a março) e outra seca longa (abril a outubro) bem definida. O clima é caracterizado como Aw, ou seja, tropical quente, com chuvas de verão e temperaturas médias anuais entre 22 e $24^{\circ} \mathrm{C} \mathrm{e}$ pluviosidade média anual entre 700 e $1100 \mathrm{~mm}$ (Koppen 1948).

Os planteis de ovinos visitados eram constituídos principalmente por animais mestiços da raça Santa Inês e possuíam em média 145 animais. Durante as visitas, todos os animais foram vistoriados para identificação de miíases, observando-se o local da ferida e pesquisando-se a possível causa do ferimento. Os dados de ocorrência das miíases foram analisados pelo teste do qui-qua- drado, considerando-se significativas as diferenças com $\mathrm{P}<0,05$. Para identificação parasitológica, larvas viáveis provenientes das feridas foram recolhidas, lavadas em solução salina estéril e cultivadas em frascos com serragem estéril para a obtenção dos adultos e classificação de acordo com Bowman et al. (2006).

Após o diagnóstico, práticas terapêuticas foram realizadas nos animais parasitados. Primeiramente, os animais foram isolados do rebanho em um local de fácil acesso, para facilitar o tratamento. Para tal, foi procedida a tricotomia e as áreas acometidas eram lavadas com água morna filtrada. Posteriormente, foi aplicada solução 50\% éter/álcool 92 ํㅡㄹ para facilitar a retirada das larvas com o auxilio de pinças. Foi aplicada a tintura de iodo a $5 \%$ em toda lesão e logo após foi administrado o larvicida trichlorphon, na forma de unguento. Para evitar re-infestações, os proprietários foram orientados a procederem inspeção diária nos animais acometidos, realizar o tratamento tópico recomendado e, em casos de feridas muito amplas (com diâmetro superior a $5 \mathrm{~cm}$ ) administrar doramectina $(200 \mu \mathrm{g} / \mathrm{kg}$ de peso corporal (pc), via subcutânea.

\section{RESULTADOS E DISCUSSÃO}

\section{Ocorrência}

Os resultados indicaram que em todos os plantéis visitados ocorreram miíases, totalizando 50 casos ao longo do ano de estudo. A maior incidência foi nos meses de março e abril $(\mathrm{P}<0,05)$, sendo registrados $22 \%$ e $18 \%$ dos casos, respectivamente como demonstrado no Quadro 1. Atenção especial deve ser adotada para a inspeção dos animais durante esses meses em regiões com características climáticas semelhantes à área estudada. Em um estudo da flutuação da mosca Cochliomyia hominivorax em armadilhas no estado de Mato Grosso, Brasil, Gomes et al (1998) reportaram que apesar de não terem capturado grande número de adultos, a presença foi constatada em todos os meses do ano. Entretanto, no mês de março foi verificado o maior número de adultos capturados, o que corrobora com os dados de ocorrência de miíases deste estudo, uma vez que maiores populações poderiam favorecer a maior incidência de lesões.

Segundo Alahmed (2004) a ocorrência de miíases ocasionadas por Chrysomya spp. em ovinos criados na região de Riyadh, Arábia Saudita, também foi significativamente maior para os meses com maiores umidades relativas do ar, correspondendo a $60 \%$ dos casos.

Os resultados dos cultivos de larvas provenientes de duas propriedades produziram adultos da espécie Cochliomyia hominivorax. Para as demais propriedades, as lesões possuíam larvas inviáveis para o cultivo e identificação. Em outro estudo no estado de São Paulo, Brasil, por Madeira et al. (2000) , essa espécie também foi identificada. Em 89,5\% das propriedades foi relatada a presença de ectoparasitas no rebanho, sendo Cochliomyia hominivorax o ectoparasita mais frequente $(72,5 \%)$, seguida por larvas Dermatobia hominis $(45,0 \%)$. Foi constatado que as miíases ocasionaram grandes prejuízos econômicos e a prevalência foi $100 \% \mathrm{em}$ rebanhos com mais de 500 animais e a infestação foi maior na primavera e no verão (Madeira et al. 2000).

Além de Cochliomyia hominivorax, causando míase primária, há registros que as espécies do gênero Chrysomya causam miíases secundárias em animais domésticos (Madeira et al. 2000). No Brasil, Chrysomya albiceps foi detec- 
tada em bovinos e ovinos (Oliveira 1985, Madeira 2001), ocorrendo em associação com $C$. hominivorax em ovinos. Segundo Madeira (2001), as miíases causadas por essa espécie no Brasil podem ser apenas secundárias, não havendo evidências que possam confirmar a sua capacidade de iniciar uma lesão no tecido.

\section{Regiões anatômicas acometidas}

Os locais de maiores ocorrências das lesões foram as patas $(34 \%, \mathrm{P}<0,05)$, orelhas $(16 \%)$ e umbigo $(10 \%)$ conforme demonstrado no Quadro 2. A ocorrência não variou de forma significativa entre patas anteriores (12 casos) e posteriores (15 casos). Existem situações em que, dependendo da localização, as infestações se tornam profundas, provocando a morte dos animais por hemorragia ou inviabilizando-os quando destroem a glândula mamária, o sistema reprodutor ou locomotor. Especialmente em pequenos ruminantes as larvas das moscas podem destruir tecidos desses sistemas em períodos inferiores a 24 horas e na maioria das vezes o animal fica mutilado (Teixeira et al. 2008).

Entretanto, Farkas et al. (1997) e Al-Eissa et al. (2008), em estudos realizados respectivamente na Hungria e na
Síria, constataram que os órgãos genitais foram os locais mais comuns de infestação por miíases em ovinos. A epidemiologia de miíases em ovinos criados na Holanda indicou que a região mais acometida foi a cauda dos animais e foram relacionadas principalmente a elevadas temperaturas e umidade relativa do ar (Snoep et al. 2002). Esses relatos podem sugerir que diferenças de manejo e a região geográfica de criação dos animais possam influenciar os locais de ocorrências das lesões, ou possivelmente ás espécies de moscas prevalentes em cada região geográfica.

Acredita-se que os locais de ocorrência possam ser influenciados pela espécie do hospedeiro. Veríssimo \& Franco (1994) relataram para um rebanho com aproximadamente 700 cabeças de bovinos mestiços que as miíases foram mais frequentemente localizadas na região mediana e ventral do períneo, na inserção dorsal da cauda ou no úbere e na orelha ou pescoço, correspondendo respectivamente a $29,3 \%, 13,8 \%$ e $10,3 \%$ dos casos.

\section{Fatores predisponentes}

No presente estudo, os fatores predisponentes para as miíases mais frequentemente relatados foram às lesões por pododermatites (38\%), onfaloflebites (10\%), linfa-

\begin{tabular}{|c|c|c|c|c|c|}
\hline Mês/ano & Índice & $\begin{array}{c}\text { Temperatura } \\
\text { Pluviométrico }(\mathrm{mm})\end{array}$ & $\begin{array}{l}\text { Umidade } \\
\left(\text { média }{ }^{0} \mathrm{C}\right)\end{array}$ & $\begin{array}{l}\text { Número } \\
\text { de casos }\end{array}$ & $\begin{array}{l}\text { Ocorrência } \\
(\%)\end{array}$ \\
\hline Set/06 & 0,0 & 23,2 & 45 & 4 & 8 \\
\hline Out/07 & 13,3 & 26,0 & 42 & 3 & 6 \\
\hline Nov/06 & 72,5 & 26,7 & 52 & 4 & 8 \\
\hline Dez/06 & 101,8 & 24,9 & 67 & 0 & 0 \\
\hline Jan/07 & 139,1 & 24,9 & 74 & 4 & 8 \\
\hline Fev/07 & 264,1 & 23,4 & 80 & 4 & 8 \\
\hline Mar/07 & 146,0 & 24,1 & 68 & $11^{*}$ & 22 \\
\hline Abr/07 & 16,4 & 23,6 & 69 & $9 *$ & 18 \\
\hline Mai/07 & 2,2 & 21,7 & 64 & 4 & 8 \\
\hline Jun/07 & 0,0 & 20,5 & 60 & 4 & 8 \\
\hline Jul/07 & 0,0 & 20,9 & 56 & 0 & 0 \\
\hline Ago/07 & 0,0 & 21,0 & 49 & 3 & 6 \\
\hline
\end{tabular}

* Indica diferença significativamente maior com valor de $\mathrm{P}<0,05$ no teste do qui-quadrado.

Quadro 2. Local de ocorrência e fatores predisponentes relacionados às miíases em ovinos criados no norte de Minas Gerais

\begin{tabular}{|c|c|c|c|c|c|}
\hline \multicolumn{3}{|c|}{ Locais de ocorrências } & \multicolumn{3}{|c|}{ Fatores relacionados } \\
\hline & $\mathrm{n}$ & Frequência\% & & $\mathrm{n}$ & Frequência\% \\
\hline Olho & 1 & 2 & Pododermatite & $19 *$ & 38 \\
\hline Cauda & 1 & 2 & Linfadenite & 3 & 6 \\
\hline Pescoço & 3 & 6 & Mastite & 2 & 4 \\
\hline Patas & $17^{*}$ & 34 & Onfaloflebite & 5 & 10 \\
\hline Umbigo & 5 & 10 & Berne & 3 & 6 \\
\hline Orelhas & 8 & 16 & Parto & 1 & 2 \\
\hline Vulva & 1 & 2 & Brinco & 1 & 2 \\
\hline Costado & 3 & 6 & Arame & 2 & 4 \\
\hline Úbere & 2 & 4 & Colar & 2 & 4 \\
\hline Região mandibular & 1 & 2 & Não identificado & 12 & 24 \\
\hline Região torácica & 4 & 8 & & & \\
\hline Dorso & 1 & 2 & & & \\
\hline Membro anterior & 3 & 6 & & & \\
\hline Total & 50 & 100 & & 50 & 100 \\
\hline
\end{tabular}

* Indica diferença significativamente maior com valor de $\mathrm{P}<0,05$ no teste do qui-quadrado. 
denite (6\%) e dermatobiose (6\%). Esses dados indicam a importância dessas doenças para o controle e prevenção das miíases. Três entre quatro casos relacionados a mortes estavam associados às pododermatites e para um quarto animal, essa doença, juntamente com a miíase, culminou na amputação de um membro anterior. Pododermatites e onfaloblebites foram detectadas em maiores frequências nos meses de março e abril, indicando uma associação direta com as miíases neste presente estudo. Foram também observados casos associados à mastite crônica, partos distócicos, lesões provocadas por brincos e colares de identificação e cerca de arame (Quadro 2). Os borregos estão sujeitos a miíases já nas primeiras horas de vida, uma vez que as moscas são atraídas para as bordas do cordão umbilical, ainda não cicatrizado. Matrizes com partos distócicos ou com retenção de placenta também favorecem a presença das moscas de miíases. As intervenções relacionadas ao manejo, como castrações, descornas, ferimentos em cercas de arame farpado e feridas causadas nas infestações por carrapatos em ovinos ou por larvas de Dermatobia hominis podem também ocasionar ferimentos com perda de integridade dos tecidos, contribuindo com a iniciação das lesões (Bowman et al. 2006, Teixeira et al. 2008).

Segundo um relato de Veríssimo (2003), as lesões de miíases foram detectadas no umbigo de bezerros e cordeiros recém-nascidos. Especificamente para bovinos as lesões foram associadas à castração e nas orelhas foram relacionadas a alta infestação por carrapatos. Em ovinos, as lesões foram detectadas no pavilhão auricular, após a instalação de brincos, e no ferimento causado por caudectomia, tosquia e por um carcinoma epidermoide de células escamosas.

Gomes et al. (2006), relataram que em uma ovelha que havia sofrido pequenas escoriações na vulva, durante o processo de inseminação artificial, foi detectada a infestação por Cochliomyia hominivorax. Posteriormente, no mesmo animal foi verificada miíase cutânea secundária, de grande extensão, provocada por Chrysomya sp. nas regiões lombar, sacral e perineal. Segundo os autores, essa colonização ocorreu, possivelmente, em função das secreções e odores produzidos pela míase primária. A presença de tecido necrótico, da oleosidade e descamação da pele, da lã comprida com retenção de exsudatos foram fatores favorecedores. As larvas se alimentavam da mistura superficial, lesionando a epiderme do animal, culminando com o aumento das lesões.

\section{Tratamento e medidas de controle}

Para a maioria dos casos detectados neste estudo, o criador ou tratador já haviam aplicado óleo queimado ou repelente com organofosforados nas lesões, ocasionando a morte das larvas localizadas na superfície das feridas. Entretanto, após a higienização e debridamento das feridas, muitas larvas vivas foram encontradas. Para os cinquenta ovinos com míases que foram tratados com as práticas adotadas neste estudo, 46 deles apresentaram cura clínica e parasitológica entre sete e 30 dias. Quatro animais que possuíam lesões profundas e crônicas nas patas (três matrizes) e no ventre (um reprodutor), ambos com gran- de perda de tecidos e contaminações secundárias microbianas, morreram. Para uma outra matriz foi necessária a amputação do membro anterior e para outra foi removido cirurgicamente a orelha e, posteriormente, ambas apresentaram cura após 30 dias de tratamentos tópicos, com limpeza diária e aplicação de unguento, além da administração subcutânea de enrofloxacina $(2,5 \mathrm{mg} / \mathrm{kg}$ de pc durante sete dias) e doramectina $(200 \mu \mathrm{g} / \mathrm{kg}$ de $\mathrm{pc})$.

Os ovinos que apresentam miíases tornam-se inquietos, pastejam menos, perdem peso e frequentemente o quadro culmina com a morte, devido às hemorragias e toxemias originadas de infecções bacterianas secundárias (Bowman et al. 2006, Teixeira et al. 2008). Caballero et al. (1996), em uma pesquisa para isolar e identificar microrganismos associados com míases, encontrou trinta e oito diferentes espécies bacterianas nos exudatos coletados antes, durante e após o ciclo parasitário. Veríssimo (2003) relata que em casos de mí́ases no pavilhão auricular, com possibilidade de atingir o ouvido interno, deve-se sempre preconizar a administração de antibiótico sistêmico para evitar infecções secundárias, que podem levar o animal ao óbito. Recente estudo indicou que o tratamento local da ferida com óleo de terebintina, obtido da destilação de resinas de coníferas, associada à administração intramuscular de penicilina e estreptomicina apresentou alta eficácia para a cura de miíases em bovinos (Rahman et al. 2009).

Muitos produtores utilizam para tratamento apenas a administração de produtos larvicidas em sprays, sendo esses considerados frequentemente bons repelentes quando usados de forma correta. Porem, tais produtos não possuem efeito larvicida satisfatório no controle de larvas instaladas profundamente nos tecidos (Madeira et al. 1998). Em alguns casos, tem-se suspeitado da resistência de algumas populações de moscas aos produtos à base de organofosforados (Veríssimo \& Franco 1994).

Devido à alta susceptibilidade dos ovinos à miíase, é necessário adoção de programas preventivos baseados nos fatores predisponentes identificados e, quando instalada, deve-se realizar o tratamento precocemente. A intervenção imediata evita que se crie condição favorável para as larvas completarem o ciclo evolutivo e aumentarem a população das moscas na região. Ferimentos desnecessários devem ser evitados e quando ocorrerem, a assepsia deve ser imediata, evitando-se a postura das moscas.

Tratamento do umbigo dos recém-nascidos deve ser realizado imediatamente após o nascimento com tinturas de iodo a 5-10\%. Animais com lesões ou feridas nas patas devem ser separados do rebanho, tratados e monitorados diariamente até a cura completa das lesões, que especificamente para essa região anatômica apresentam difícil cicatrização, ocasionada pela constante contaminação microbiana.

Cercas de arame farpado, instalações com obstáculos e farpas, instrumentos pontiagudos e cães ou outros animais ferozes devem ser evitados. As pastagens devem estar sempre limpas e ter lotação de animais adequada evitando brigas e predisposições a ferimentos.

As marcações com ferro quente ou perfurações das orelhas devem ser evitadas e infestações de berne, linfadenite 
e pododermatite devem ser monitoradas e controladas. Os animais doentes devem ficar isolados em um local confinado até a cura da ferida para facilitar as intervenções e tratamentos. Outro aspecto importante é que esse animal doente, quando mantido junto com os demais, acaba sendo dominado e frequentemente não tem acesso á alimentação e à água.

É imprescindível que antes da cura das feridas se realize tricotomia, limpeza e a aplicação de solução com éter/ álcool. Para a cura das bicheiras deve ser utilizada a tintura de iodo a $5 \%$ primeiramente. Posteriormente, pode ser utilizado um dos vários compostos químicos larvicidas, apresentados em pós, líquidos, ungüentos e sprays, os quais estão associados com antimicrobianos, anti-sépticos, piretróides, cicatrizantes e adstringentes. Os ungüentos têm apresentado bons resultados principalmente nos períodos de maior precipitação pluviométrica. Os inseticidas e larvicidas comerciais geralmente possuem ação residual curta e para evitar re-infestações, exigem inspeção diária e tratamentos freqüentes nos animais.

Em uma pesquisa avaliando-se os efeitos da administração de ivermectina e permetrina no controle de miíases em ovinos, foi observada a redução significativa no número de larvas vivas em comparação ao grupo não tratado. Ambas as drogas reduziram a re-infestação, com proteção total durante 22 dias, no grupo tratado com ivermectina. Para o grupo tratado com permetrina, a proteção foi apenas parcial e prevaleceu durante 13 dias. A ivermectina foi mais eficaz para a erradicação das larvas das feridas infestadas, reduziu os prejuízos ocasionados pelas lesões nos animais e foi significativamente mais efetiva para evitar o surgimento de pupa e adultos das moscas (Al-Eissa et al. 2008). Esse fármaco apresenta mecanismo de ação semelhante à doramectina, preconizada neste presente estudo, corroborando a importância de medicação dos animais para a cura das lesões.

Ivermecitina e doramectina têm demonstrado boa eficácia na prevenção das miíases e devem ser utilizadas rotineiramente como curativo e/ou preventivo nos ferimentos cirúrgicos (Sanavria et al. 1996, Al-Eissa et al. 2008). Esses produtos são essenciais para se evitar as re-infestações nas lesões, como pôde ser observado nesta presente pesquisa.

\section{CONCLUSÕES}

Os dados obtidos indicaram que em todos os planteis de ovinos ocorreram miíases, totalizando 50 casos.

A incidência foi maior nos meses de março e abril e os locais de maior ocorrência das lesões foram as patas, as orelhas e o umbigo.

Os resultados indicam a necessidade da implantação de programas preventivos baseados nos fatores observados neste estudo.
Agradecimentos.- Este trabalho teve apoio do Conselho Nacional de Desenvolvimento Científico e Tecnológico (CNPq), Fundação de Amparo à Pesquisa do Estado de Minas Gerais (Fapemig), Fundo de Desenvolvimento Científico e Tecnológico Fundo (Fundeci, Banco do Nordeste) e Pró-reitoria de pesquisa da Universidade Federal de Minas Gerais.

\section{REFERÊNCIAS}

Alahmed A.M. 2004. Myiasis in sheep farms in Riyadh Region, Saudi Arabia. J. Egypt. Soc. Parasitol. 34:153-160.

Al-Eissa G.S., Gammaz H.A., Mohamed Hassan M.F., Abdel-Fattah A.M., AlKholany K.M. \& Halami M.Y. 2008. Evaluation of the therapeutic and protective effects of ivermectin and permethrin in controlling of wound myiasis infestation in sheep. Parasitol. Res. 103:379-385.

Bowman D.D., Lynn R.C., Eberhard M.L. \& Alcaraz A. 2006. Parasitologia Veterinária de Georgis. 8aㅡ. ed. Editora Malone, Tamboré. 422p.

Caballero M., Hernández G., Poudevigne FI. \& Ruiz-Martínez I. 1996. Isolation and identification of bacteria associated with the screwworm fly Cochliomyia hominivorax, coquerel and its myiasis. Ann. N.Y. Acad. Sci. 23:248-254.

Farkas R., Hall M.J. \& Kelemen F. 1997. Wound myiasis of sheep in Hungary. Vet. Parasitol. 69:133-144.

Fortes E. 2004. Parasitologia Veterinária. 4ํa ed. Ícone Editora, São Paulo. $607 p$.

Gomes A., Koller W.W., Honer M.R. \& Silva R.L. 1998. Flutuação populacional da mosca Cochliomyia hominivorax (Coquerel, 1858) (Diptera; Calliphoridae) capturada em Armadilhas Orientadas pelo Vento (W.O.T.), no Município de Campo Grande, MS. Rev. Bras. Parasitol. Vet., 7: 41-45.

Gomes F.C., Monteiro J.A.S., Koller W.W. \& Gomes A. 2006. Caso de miíase cutânea secundária em ovino em Mato Grosso do Sul, Brasil. Biológico, São Paulo, 68:27-28.

Guimarães J.H. \& Papavero N. 1999. Myiasis in man and animals in the neotropical region, bibliographic database. Plêiade, FAPESP, São Paulo. 308p.

Koppen W. 1948. Climatologia. Panamericana, Buenos Aires. 478p.

Madeira N.G., Amarante A.F.T. \& Padovani C.R. 1998. Effect of management practices on screw-worm among sheep in São Paulo State, Brazil. Trop. Anim. Hlth Prod. 30:149-157.

Madeira N.G., Amarante A.F. \& Padovani C.R. 2000. Diversity of ectoparasites in sheep flocks in São Paulo, Brazil. Trop. Anim. Hlth Prod. 32:225-232.

Madeira N.G. 2001. Would Chrysomya albiceps (Diptera: Calliphoridae) be a beneficial species? Arq. Bras. Med. Vet. Zootec. 53:157-161.

Oliveira C.M.B. 1985. Chrysomya albiceps, novo agente de miíase cutânea secundária de ovinos no Brasil. Pesq. Agropec. Bras. 20:497-498.

Rahman M.A., Hossain M.A. \& Alam M.R. 2009. Clinical evaluation of different treatment regimes for management of myiasis in cattle. Bangl. J. Vet. Med. 77:348-352.

Sanavria A., Muniz R.A., Gonçalves L.C.B., Rew R.S. \& Silva D.S.F. 1996. Eficácia profilática de doramectina contra infestações naturais por Coclhiomyia hominivorax (Colquerel, 1858) em bovinos, após castração. Revta Bras. Parasitol. Vet. 5:7-10.

Snoep J.J., Sol J., Sampimon O.C., Elbers A.R.W., Scholten H.W. \& Borgsteede F. H.M. 2002. Myiasis in sheep in the Netherlands. Vet. Parasitol. 106:357-363.

Teixeira L.M. \& Duarte E.R. 2008. Cuidados com miíases ou bicheira. Revta o Berro 116:94-97.

Veríssimo C.J. 2003. Morte de ruminantes devido à infecção na orelha conseqüente à miíase causada por Cochliomyia hominivorax (Coquerel, 1858). Arqs Inst. Biológico, São Paulo, 70(2):187-189,

Veríssimo C.J. \& Franco A.V.M. 1994. Relação entre infestação pelo carrapato Boophilus microplus e ocorrência de miíase em bovinos mestiços. Bolm Ind. Anim., Nova Odessa, 51:3-5. 